И СРАВНИТЕЛЬНОЕ ПРАВОВЕДЕНИЕ

DOI: https://doi.org/10.15688/jvolsu5.2016.4.24

UDC 341.161

LBC 67.39

\title{
BASEL II INTERNATIONAL CONVENTION: FOUR PRINCIPLES OF SUPERVISORY REVIEW PROCESS
}

\author{
Marina V. Goncharova \\ Plekhanov Russian State University of Economics (Volgograd Branch), Volgograd, Russian Federation
}

\begin{abstract}
Introduction. The article continues the study of the Basel II, the author examines the four basic principles of the supervisory process. Structurally, this paper examines the position of the Second component of Basel II (Part III of the Agreement), this component integrates rules-principles of the process of supervision of credit institutions by national authorities (central banks) in the member countries of the Basel II - International Convergence of Capital Measurement and Standards capital: new approaches. The purpose of research is to reveal the four rules-principles of supervision of compliance with the provisions of the banks on the measurement of capital and capital standards by the competent authorities. Methods. We used in combination the methods of scientific knowledge, including basic - methods of system analysis and comparative law. The results justified that the Basel II supervisory process is intended to ensure the adequacy of banks' capital available to cover all risks and encourage banks to develop and modernize the methods of monitoring and risk management, which banks are exposed to. We established the responsibility of heads of banks for the development of the bank's capital assessment procedures for determining the level of capital corresponding to the nature of the risk and control environment of the bank. Supervisors assess the ability of banks to determine capital requirements regarding risks, intervene in this process, in dialogue with the banks to ensure the rapid adoption of measures to reduce the risks of capital replenishment banks. The growth of bank risk is neutralized by an increase in bank capital, the strengthening of the risk management system, the establishment of internal limits, increase of allocations to reserves, improvement of internal control. Conclusions. The Basel II contains four basic principles of supervisory review, which complement the detailed Core Principles for Effective Banking Supervision (Basel Committee on Banking Supervision, September 1997), and Core Principles Methodology (Basel Committee on Banking Supervision, October 1999).
\end{abstract}

Key words: bank, risks, capital, sufficiency, principles, regulation, supervision, international convention.

УДК 341.161

ББК 67.39

\section{МЕЖДУНАРОДНОЕ СОГЛАШЕНИЕ БАЗЕЛЬ ІІ:} ЧЕТЫРЕ ПРИНЦИПА НАДЗОРНОГО ПРОЦЕССА

\author{
Марина Вячеславовна Гончарова \\ Российский государственный экономический университет им. Г.В. Плеханова (Волгоградский филиал), \\ г. Волгоград, Российская Федерация
}

Введение: в статье продолжается изучение Соглашения Базель II, автор рассматривает четыре базовых принципа надзорного процесса. Структурно в данной работе исследуются положения Второго компонента 


\section{МЕЖДУНАРОДНОЕ ПРАВО И СРАВНИТЕЛЬНОЕ ПРАВОВЕДЕНИЕ}

Базеля II (часть III Соглашения), данный компонент интегрирует в себе правила-принципы процесса надзора за кредитными организациями национальными органами (центральными банками) в странах-участницах Соглашения Базель II - «Международной конвергенции измерения капитала и стандартов капитала: новые подходы». Цель исследования - раскрыть четыре правила-принципа надзора за соблюдением банками положений об измерении капитала и стандартов капитала компетентными органами. Методы: применены в совокупности методы научного познания, среди которых основные - методы системности, анализа и сравнительно-правовой. Результаты: обосновано, что надзорный процесс Базеля II предназначен гарантировать достаточность у банков имеющегося капитала для покрытия всех рисков, а также стимулировать банки разрабатывать и модернизировать методы мониторинга и управления рисками, которым банки подвержены. Установлена ответственность руководителей банков за разработку ими процедур оценки капитала банка, за определение уровня капитала, соответствующего характеру рисков и контрольной среде банка. Надзорные органы оценивают способность банков определять требования к капиталу относительно рисков, вмешиваются в этот процесс, ведут диалог с банками, обеспечивая быстрое принятие мер для уменьшения рисков, пополнения банками капитала. Рост банковских рисков нейтрализуется увеличением капитала банка, укреплением системы управления рисками, установлением внутренних лимитов, повышением отчислений в резервы, совершенствованием внутреннего контроля. Выводы: Базель II содержит четыре основных принципа надзорного процесса, которые детально дополняют Основные принципы эффективного банковского надзора (Базельский комитет по банковскому надзору, сентябрь 1997 г.) и Методологию основных принципов (Базельский комитет по банковскому надзору, октябрь 1999 г.).

Ключевые слова: банк, риски, капитал, достаточность, принципы, регулирование, надзор, международное соглашение.

\section{Введение}

«Международная конвергенция измерения капитала и стандартов капитала» 1988 г. (International convergence of capital measurement and capital standards) - Соглашение, известное в российской литературе и банковской практике как Базель I - Basel Capital Accord, paccматривается в нашей статье [1]. Мы продолжим исследование соглашения, развивающего Базель I, - «Международной конвергенции измерения капитала и стандартов капитала: новые подходы» - Соглашения Базель II [8], при этом, обращаясь к данной довольно сложной проблематике, рекомендуем использовать весь цикл наших статей (см.: [1-7]).

В части II в составе Первого компонента Базеля II регламентируются технологии снижения кредитных рисков в рамках стандартизированного подхода [4]. Этот первый подход основывается на внешних оценках авторитетных рейтинговых агентств. Второй подход, также в части II в составе Первого компонента Базеля II, предусматривает возможность использования банками для оценки кредитного риска собственных рейтинговых алгоритмов. Затем в части II в составе Первого компонента Базеля II регламентируются меры по нейтрализации кредитного риска на основе использования банками рамочного подхода секъюри- тизации [5]. Далее-правила регулирования операционного риска [6]. Завершается Первый компонент Базеля II (часть II Соглашения) положениями о порядке формирования и регулирования банком торгового портфеля как особого набора финансовых инструментов [7].

Продолжая изучение Соглашения Базель II, рассмотрим далее четыре базовых принципа надзорного процесса. Уточним, что структурно здесь мы исследуем положения Второго компонента Базеля II (часть III Соглашения), данный компонент интегрирует в себе правила-принципы процесса надзора за кредитными организациями национальными органами (центральными банками) в странах-участницах Соглашения Базель II.

\section{Часть I}

Первый принцип: банк способен оценивать свой капитал адекватно рискам и поддержсивать на достаточном уровне.

Руководители банка (высший совещательный орган, исполнительный орган) организуют регулярный процесс стресс-тестирования для выявления возможных в будущем неблагоприятных для банка событий, а также несут ответственность за наличие у банка капитала, который соразмерен его рискам на конкретной стадии цикла деловой активнос- 
ти. Данный процесс включает пять взаимосвязанных разновидностей контроля:

1. Надзор со стороны руководителей банка. Руководители банка обязаны знать уровень и структуру рисков, которые принимает на себя банк, понимать, каково соотношение риска с уровнем капитала банка. В рамках стратегического плана руководители банка обязаны устанавливать потребности банка в капитале, планировать капитальные расходы, иметь внешние источники пополнения капитала. Совет директоров банка устанавливает предел толерантности банка к риску, оценочные рамки различных рисков, формирует систему соответствия уровня риска размеру капитала банка. Кроме того, совет директоров банка определяет средства и процедуры внутреннего контроля, доводит все указанные решения в документированном виде до сотрудников.

2. Обоснованная оценка капитала банка. Базелем II в $§ 731$ рекомендованы четыре элемента обоснованной оценки капитала банка:

- процедуры, предусматривающие выявление и измерение (возможность рассчитывать) уровня каждого из рисков, которым подвержен банк, а также представление отчетности об этих рисках;

- алгоритм сопоставления размера капитала с общим уровнем риска;

- порядок расчета предельных значений достаточности капитала, учитывающих стратегические цели банка и соответствующих этапам бизнес-плана банка;

- процесс непрерывного ведения внутренних проверок и аудита, контролирующий целостность процесса управления рисками в целом.

3. Оценка банком рисков. Признавая, что не все риски можно измерить, Базельский комитет устанавливает, что при оценке должны учитываться следующие пять видов риска, которым подвержен каждый банк и которые следует считать существенными.

Кредитный риск - это вероятность неплатежа заемщиком суммы кредита (части суммы) по утвержденному банком графику платежей. Кредитный риск необходимо оценивать как по неплатежам единичных заемщиков, так и на уровне кредитного портфеля в целом. При выдаче кредитов оценку достаточности капитала банка следует проводить по четырем направлениям: внутренние рейтинговые системы оценки риска; анализ и дифференциация требований в кредитном портфеле; секъюритизация требований и сложные кредитные деривативы; концентрация риска по крупным кредитам единичным заемщикам [5].

Операционный риск - это вероятность получения банком убытков вследствие ненадлежащего осуществления внутренних процедур, действий работников и технических систем самого банка, а также вследствие внешних негативных для банка событий. Базель II включает в операционный риск еще и юридический риск, который является «малой матрешкой внутри большой матрешки» и представляет собой вероятность получения банком убытков прежде всего в виде штрафов, пеней, неустоек, взысканий сумм надзорным органом, в виде расходов проигравшего иск ответчика и др. [6] Неспособность банка эффективно управлять операционным риском влечет искаженное представление о соотношении риска и доходности банковских операций, увеличивает вероятность крупных финансовых потерь.

Рыночный риск оценивается банком путем расчета стоимости под риском либо по правилам стандартизированного подхода Базеля II [2-4].

Процентный риск - это вероятность неплатежа заемщиком суммы процентов за кредит (части суммы процентов) по утвержденному банком графику платежей. Данный риск рассчитывается как сумма возможных неплатежей процентов по каждому заемщику и по кредитному портфелю банка в целом. Оцениваются текущие остатки сумм процентов, даты изменений процентных ставок, сроки состоявшихся платежей.

Риск потери ликвидности - это вероятность снижения банком суммы денежных средств на его корреспондентских счетах и в кассе ниже уровня, который необходим для своевременного и в полном объеме исполнения банком всех публичных платежей и договорных денежных обязательств. От размера капитала банка прямо зависит его способность получать ликвидность (деньги) на его корреспондентские счета и в кассу, тем более в кризисные моменты. Достаточность капитала должна оцениваться банком адекватно его спо- 


\section{МЕЖДУНАРОДНОЕ ПРАВО И СРАВНИТЕЛЬНОЕ ПРАВОВЕДЕНИЕ}

собности поддерживать ликвидность на надлежащем уровне, а также с учетом ликвидности рынков, где банк проводит свои операции.

4. Мониторинг и отчетность. Руководители банка обязаны создать систему слежения и отчетности по каждому виду риска, а также систему оценки влияния на размер капитала динамики каждого риска. Они регулярно получают отчеты о текущих рисковых для банка ситуациях и соответствующих потребностях банка в капитале. Указанные отчеты позволяют руководителям банка:

- оценивать уровень и динамику существенных рисков, то, как они соотносятся с достаточностью капитала;

- понимать обоснованность допущений, присутствующих в системе оценки достаточности капитала банка;

- видеть соблюдение банком установленных нормативов достаточности капитала: имеется ли в наличии у банка достаточный капитал, необходимый для покрытия существенных рисков;

- рассчитывать будущую потребность банка в капитале адекватно представленным в отчетах уровням рисков, корректировать при необходимости стратегический бизнес-план банка.

5. Мониторинг системы внутреннего контроля. Руководители банка обязаны систематически следить за процессом управления рисками, обеспечивая его целостность, надежность и обоснованность, анализируя данный процесс по следующим направлениям:

- соответствие процесса оценки капитала масштабам и сложности деятельности банка;

- предупреждение случаев значительной подверженности банка риску и случаев значительной для банка концентрации риска;

- полнота и достоверность исходных данных, которые банк применяет, делая оценку достаточности капитала банка;

- надежность и обоснованность используемых в рамках процесса оценки ее алгоритмов;

- стресс-тестирование банка и анализ неточностей в исходных данных.

\section{Часть II}

Второй принциип: надзорные органы проверяют определение банками доста- точности капитала, соблюдение нормативов достаточности, предпринимают меры реагирования.

Надзорные органы непрерывно отслеживают и оценивают степень успешности каждого банка в создании надежного механизма оценки достаточности своего капитала, позиций под риском, соответствия требованиям к капиталу, качества имеющегося у банка капитала. Надзорные органы здесь нацелены на то, чтобы знать уровень качества управления рисками в банке, жизнеспособность систем внутрибанковского контроля, но не на то, чтобы подменять руководителей банка. Практически надзорные органы реализуют инспекции на местах; дистанционные проверки; встречи и совещания с руководителями банка; контроль работы внешних аудиторов, проверяющих вопросы достаточности капитала.

Надзорными органами в каждом банке проверяется полнота охвата существенных рисков в процессе управления ими, адекватность показателей рисков для оценки достаточности капитала, правильность использования этих показателей рисков при установлении лимитов операций банка, результаты деятельности по бизнес-линиям во взаимосвязи с управлением рисками. Также проверяются результаты стресстестирования, их влияние на поддержание банком капитала на достаточном уровне.

В части оценки банком достаточности капитала надзорные органы проверяют: соответствие ориентиров уровня капитала банка всем факторам риска и самой операционной среде; надлежащее соблюдение банком этих ориентиров и их контроль руководителями банка; соответствие состава капитала банка масштабам и характеру деятельности банка. Кроме того, при установлении банком уровня капитала надзорные органы принимают во внимание, насколько банк учитывает непредвиденные обстоятельства в рамках реальных внешних условий и сценариев, также надзорные органы оценивают, насколько сложность стресс-тестов соизмерима с характером операций банка.

Контрольная среда банка оценивается надзорными органами по уровню качества внутрибанковской отчетности, по способам дифференциации деловых рисков, по реальным примерам поведения руководителей банка при возникновении (изменении характера) тех или 
M.В. Гончарова. Международное соглашение Базель II: четыре принципа надзорного процесса

иных рисков. Уровень достаточности капитала банка определяется соответственно характеру его рисков, его процессу управления рисками, его системам внутреннего контроля, с учетом внешних факторов, включая влияние конкретного цикла деловой активности, макроэкономической среды.

Надзор за соблюдением минимальных стандартов и квалификационных критериев является неотъемлемой частью всего надзорного процесса. Эти минимальные стандарты позволяют надзорным органам получать полезный набор ориентиров, отражающих работу руководителей банка по эффективному управлению рисками и обеспечению достаточности капитала банка. Не менее важен надзорный процесс при проверке требований, установленных в отношении стандартизированных подходов. Цель - достижение того, чтобы инструменты, способствующие уменьшению требований к капиталу банка по Компоненту 1 [2; 3], применялись как часть испытанного документированного процесса управления рисками.

В ситуации, при которой надзорные органы не удовлетворены работой банка по оценке рисков и обеспечению им достаточности капитала, органы надзора предпринимают меры реагирования, рассмотренные ниже.

\section{Часть III}

Третий принцип: надзорные органы стимулируют банки поддержсивать уровень капитала выше минимальных нормативов.

Надзорные органы требуют от банков и поощряют их формировать и иметь буферный запас капитала, превышающий стандарт капитала по Компоненту 1 , по ряду причин:

1) большинство международных банков стремятся иметь капитал выше минимального стандарта из соображений конкуренции, чтобы рейтинговые агентства присваивали им высокие рейтинги;

2) в процессе банковской деятельности меняется ее объем, характер, степень подверженности банка рискам, это влечет колебания уровня достаточности капитала;

3) при неблагоприятной рыночной конъюнктуре в короткий срок мобилизовать дополнительный капитал может быть недопустимо дорого;
4) снижение показателя регулятивного капитала ниже минимального норматива может привести к нарушению банком законодательства, что повлечет принятие надзорными органами срочных мер по исправлению ситуации;

5) в рамках Компонента 1 при определении уровня достаточности капитала банка могут быть не учтены риски как данного банка, так и экономики в целом.

Достаточный уровень капитала банков обеспечивается надзорными органами путем установления минимального и ориентировочного коэффициентов капитала; категории капитализации банка, превышающей эти коэффициенты (например, «хорошо капитализированный банк», «адекватно капитализированный банк»).

\section{Часть IV}

Четвертый принцип: надзорные органы превентивно вмешиваются, предотвращая снижение капитала банков ниже минимального уровня, предпринимают срочные меры по исправлению положения.

В том случае, если требования, изложенные выше, банком не соблюдаются, надзорные органы обязаны принять меры. Согласно $\S 759$ Базеля II применимы усиление надзора за банком, ограничение выплаты дивидендов, требование к банку представить план восстановления уровня капитала, требование к банку мобилизовать дополнительный капитал. Надзорными органами должны применяться именно те меры, которые наиболее соответствуют конкретной ситуации, в которой в данный период оказался банк.

Увеличение капитала банка не всегда помогает решить проблемы банка в долгосрочной перспективе. Данная мера может считаться временной, при этом в сочетании с ней проводится модернизация систем и механизмов контроля, что занимает значительный промежуток времени. Впоследствии, при условии положительного эффекта такой модернизации, надзорные органы могут снять требование об увеличении банком его капитала.

\section{Результаты}

Надзорный процесс Базеля II предназначен гарантировать достаточность у банков имеюще- 


\section{МЕЖДУНАРОДНОЕ ПРАВО И СРАВНИТЕЛЬНОЕ ПРАВОВЕДЕНИЕ}

гося капитала для покрытия всех рисков, а также стимулировать банки разрабатывать и модернизировать методы мониторинга и управления рисками, которым банки подвержены.

Надзорный процесс Базеля II выделяет ответственность руководителей банков за разработку ими процедур оценки капитала банка, за определение уровня капитала, соответствующего характеру рисков и контрольной среде банка. Руководители банка ответственны за обеспечение уровня достаточности капитала банка на покрытие рисков сверх минимальных требований.

Надзорные органы оценивают способность банков определять требования к капиталу относительно рисков, при необходимости вмешиваются в данный процесс с целью ведения диалога с банками, чтобы обеспечить быстрое принятие мер для уменьшения рисков, пополнения банками капитала.

Базель II признает, что размер капитала банка, предназначенного на покрытиерисков, связан с эффективностью процесса управления рисками внутрибанковским контролем. Рост банковских рисков купируется не только увеличением капитала банка. Применимы также укрепление системы управления рисками, внутренние лимиты, повышение отчислений в резервы, совершенствование внутреннего контроля.

\section{Выводы}

Базель II в § 725-760 содержит четыре основных принципа надзорного процесса, которые детально дополняют Основные принципы эффективного банковского надзора (Базельский комитет по банковскому надзору, сентябрь 1997 г.) и Методологию основных принципов (Базельский комитет по банковскому надзору, октябрь 1999 г.). Во-первых, каждый банк должен быть способен оценивать свой капитал адекватно рискам и поддерживать на достаточном уровне; во-вторых, надзорные органы должны проверять определение банками достаточности капитала, соблюдение нормативов достаточности, предпринимать меры реагирования; в-третьих, надзорные органы должны стимулировать банки поддерживать уровень капитала выше минимальных нормативов; в-четвертых, надзорные органы должны превентивно вмешиваться, пре- дотвращая снижение капитала банков ниже минимального уровня и предпринимая срочные меры по исправлению положения.

\section{СПИСОК ЛИТЕРАТУРЫ}

1. Гончарова, М. В. Международное соглашение «Базель І»: влияние на банковское регулирование в Евросоюзе и России / М. В. Гончарова // Вестник Волгоградского государственного университета. Серия 5, Юриспруденция. - 2013. - №3 (20). - С. 120-129.

2. Гончарова, М. В. Международное соглашение «Базель ІІ»: влияние на банковское регулирование в Российской Федерации. Часть первая / М. В. Гончарова // Вестник Волгоградского государственного университета. Серия 5, Юриспруденция. - 2015. - № 1 (26). - С. 189-194.

3. Гончарова, М. В. Международное соглашение «Базель ІІ»: влияние на банковское регулирование в Российской Федерации. Часть вторая / М. В. Гончарова // Вестник Волгоградского государственного университета. Серия 5, Юриспруденция. - 2015. - № 2 (27). - С. 151-158.

4. Гончарова, М. В. Международное соглашение «Базель ІІ»: влияние на банковское регулирование в Российской Федерации. Часть третья / М. В. Гончарова // Вестник Волгоградского государственного университета. Серия 5, Юриспруденция. - 2015. - № 3 (28). - С. 179-186.

5. Гончарова, М. В. Международное соглашение «Базель II»: кредитный риск - особенности секъюритизации / М. В. Гончарова // Вестник Волгоградского государственного университета. Серия 5, Юриспруденщия. -2015. - №4 (29). - С. 160-166.

6. Гончарова, М. В. Международное соглашение «Базель ІІ»: операционный риск - особенности регулирования / М. В. Гончарова // Вестник Волгоградского государственного университета. Серия 5, Юриспруденция. - 2016. - № 2 (31). - С. 170-176.

7. Гончарова, М. В. Международное соглашение «Базель II»: торговый портфель банка - состав и регулирование / М. В. Гончарова // Вестник Волгоградского государственного университета. Серия 5, Юриспруденция. - 2016. - № 3 (32). - С. 126-132.

8. International convergence of capital measurement and capital standards: a revised framework. Electronic text data. - Mode of access: http://www.bis.org/ publ/bcbs118.htm. - Title from screen.

\section{REFERENCES}

1. Goncharova M.V. Mezhdunarodnoe soglashenie «Bazel I»: vliyanie na bankovskoe 
regulirovanie v Evrosoyuze i Rossii [Basel I international convention: influence on banking regulation in European Union and Russian Federation]. Vestnik Volgogradskogo gosudarstvennogo universiteta. Seriya 5, Yurisprudentsiya [Science Journal of Volgograd State University. Jurisprudence], 2013, no. 3 (20), pp. 120-129.

2. Goncharova M.V. Mezhdunarodnoe soglashenie «Bazel II»: vliyanie na bankovskoe regulirovanie v Rossiyskoy Federatsii. Chast pervaya [Basel II international convention: influence on the bank regulation in the Russian Federation. Part I]. Vestnik Volgogradskogo gosudarstvennogo universiteta. Seriya 5, Yurisprudentsiya [Science Journal of Volgograd State University. Jurisprudence], 2015, no. 1 (29), pp. 189-194.

3. Goncharova M.V. Mezhdunarodnoe soglashenie «Bazel II»: vliyanie na bankovskoe regulirovanie v Rossiyskoy Federatsii. Chast vtoraya [Basel II international convention: influence on the bank regulation in the Russian Federation. Part II]. Vestnik Volgogradskogo gosudarstvennogo universiteta. Seriya 5, Yurisprudentsiya [Science Journal of Volgograd State University. Jurisprudence], 2015, no. 2 (30), pp. 151-158.

4. Goncharova M.V. Mezhdunarodnoe soglashenie «Bazel II»: vliyanie na bankovskoe regulirovanie v Rossiyskoy Federatsii. Chast tretya [Basel II international convention: influence on the bank regulation in the Russian Federation. Part III]. Vestnik Volgogradskogo gosudarstvennogo universiteta. Seriya 5, Yurisprudentsiya [Science Journal of Volgograd State University. Jurisprudence], 2015, no. 3 (31), pp. 179-186.

5. Goncharova M.V. Mezhdunarodnoe soglashenie «Bazel II»: kreditnyy risk - osobennosti sekyuritizatsii [Basel II International Convention: Credit Risk - Security Features]. Vestnik Volgogradskogo gosudarstvennogo universiteta. Seriya 5, Yurisprudentsiya [Science Journal of Volgograd State University. Jurisprudence], 2015, no. 4 (29), pp. 160-166.

6. Goncharova M.V. Mezhdunarodnoe soglashenie «Bazel II»: operatsionnyy risk osobennosti regulirovaniya [Basel II International Convention: Operational Risk - Special Regulation]. Vestnik Volgogradskogo gosudarstvennogo universiteta. Seriya 5, Yurisprudentsiya [Science Journal of Volgograd State University. Jurisprudence], 2016, no. 2 (31), pp. 170-176.

7. Goncharova M.V. Mezhdunarodnoe soglashenie «Bazel II»: torgovyy portfel banka - sostav i regulirovanie [Basel II International Convention: trading portfolio - composition and regulation]. Vestnik Volgogradskogo gosudarstvennogo universiteta. Seriya 5, Yurisprudentsiya [Science Journal of Volgograd State University. Jurisprudence], 2016, no. 3 (32), pp. 126-132.

8. International convergence of capital measurement and capital standards: a revised framework. Available at: http://www.bis.org/publ/ bcbs118.htm.

\section{Information About the Author}

Marina V. Goncharova, Doctor of Economic Sciences, Professor, Department of Economics and Management, Plekhanov Russian State University of Economics (Volgograd Branch), Volga-Donskaya St., 11, 400066 Volgograd, Russian Federation, goncharova.sofia@gmail.com.

\section{Информация об авторе}

Марина Вячеславовна Гончарова, доктор экономических наук, профессор кафедры экономики и менеджмента, Российский государственный экономический университет им. Г.В. Плеханова (Волгоградский филиал), ул. Волго-Донская, 11, 400066 г. Волгоград, Российская Федерация, goncharova.sofia@gmail.com. 